\title{
Use of autologous transfusion in the management of acute traumatic haemothorax in the accident and emergency department
}

\author{
A McGhee, S Swinton, $M$ Watt
}

\begin{abstract}
A case is described where life threatening haemothorax was treated in the accident and emergency department with the aid of autotransfusion. The technique is outlined and the advantages and potential complications of the procedure are discussed. ( $($ Accid Emerg Med 1999;16:451-452)
\end{abstract}

Keywords: haemothorax; autologous transfusion

\section{Case report}

A 29 year old man was brought into the accident and emergency (A\&E) department with blunt chest injuries after an accident at an open cast mine where the personnel carrier he was in collided with a second vehicle and rolled down a steep embankment.

On arrival the patient had a Glasgow coma score of 15 and was complaining of severe chest and back pain. He was cold, clammy, and sweaty with a pulse of 92 beats $/ \mathrm{min}$ and blood pressure $93 / 63 \mathrm{~mm} \mathrm{Hg}$. There were diminished breath sounds on the right side of his chest and chest radiography showed multiple bilateral rib fractures with a haemothorax on the right.

A size $32 \mathrm{~F}$ chest drain was inserted and over 1 litre of blood drained immediately. Large intravenous access was established in both arms and crystalloid/colloid infusions were

Accepted 17 July 1999 rapidly started. Two units of type-only and eight units of fully crossmatched blood were ordered. Blood loss from the chest drain was heavy, so that despite 2 litres of crystalloid, 2.5 litres of colloid, and 5 units of blood within the first 45 minutes, the patient became progressively more shocked with increasing tachycardia and respiratory rate, and deteriorating blood pressure and conscious level. The patient was intubated with a double lumen tube. An autotransfuser was connected in place of the usual underwater seal chest drain. The $1400 \mathrm{ml}$ bag filled rapidly with blood and was transfused back into the patient under pressure. A second bag also collected $1400 \mathrm{ml}$ and $800 \mathrm{ml}$ of this was transfused back in theatre, by which time extra blood had arrived from the blood bank. In total, preoperative blood loss from the chest drain was 4 litres, of which 2.2 litres was autotransfused.

Right thoracotomy was performed and he was found to have extensive lacerations to the middle and lower lobes of the right lung, which were sutured with the aid of haemostatic sponges. Intraoperative blood loss was a further 4 litres. The patient was transferred ventilated to the intensive care unit of a neighbouring hospital due to a shortage of beds, where he made an uneventful recovery. He was extubated on the ninth day postoperatively and discharged from hospital on the 18th day.

\section{Discussion}

We believe this may be the first occasion that autotransfusion has been used in an $A \& E$ department in Scotland. In this patient severe bleeding from pulmonary lacerations caused progressive haemorrhagic shock and the rate of blood loss exceeded the blood supply available from the laboratory services at one point.

Autotransfusion is defined as the collection and reinfusion of the patient's own blood and is a well established technique. ${ }^{12}$ Autotransfusers without cell washing ability are cheap and simple devices that are routinely used in many emergency departments in the United States in the management of acute chest trauma. The device that was used in this case (Deknatel Pleur-evac A/7000) consists of a sterile 1.4 litre bag mounted in a rigid plastic container, with two tubes leading externally from the bag, one are less than in whole blood,

- Free haemoglobin concentration is higher in autotransfused blood with theoretical risk of acute tubular necrosis but no cases have ever been reported ${ }^{6}$ 


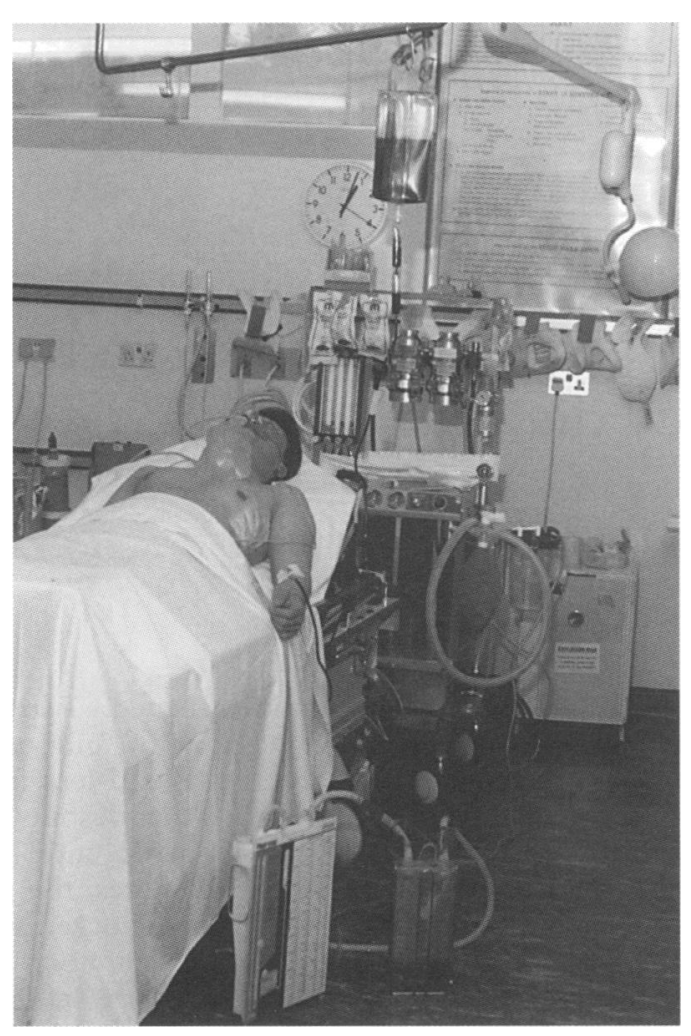

Figure 1 Autotransfuser in use as giving set and second autotransfuser connected to chest drain.

of which connects onto a standard chest drain tube. Blood draining through this tube passes through a microemboli filter $(20-40 \mu \mathrm{m})$ into the bag, under wall mounted suction. Once the bag is full the connections are clipped off, the bag removed from the container, raised, and used like a standard unit of packed red cells with an inlet at the bottom which takes a bloodgiving set. The blood typically does not coagulate in the device because of defibrination by passage over pleural surfaces and the mechanical action of the heart. ${ }^{3}$ However it is generally recommended that citrate, phosphate, dextrose anticoagulation solution should be added, ${ }^{4}$ one part in seven, as injuries to the great vessels can bleed at a fast enough rate to allow coagulable blood to enter the device.

The advantages and complications of using autotransfusion are listed in table 1 and the autotranfuser is shown in fig 1 .

\section{Conclusion}

We have presented a case where the use of an autotransfuser in the emergency situation was probably life saving. Such devices are well established in the United States as being simple and inexpensive to use in the emergency department. So far they have been little used in the UK, but we believe that their potential in the management of life threatening haemothorax is substantial and now use autotransfusion whenever such a situation arises.

Conflict of interest: none.

Funding: none.

1 Davidson SJ. Emergency unit autotransfusion. Surgery 1978;84:703-7.

2 Brown AL, Debenham MW. Autotransfusion: use of blood from haemothorax. $\mathscr{f} A M A$ 1931;96:1223-5.

3 Broadie TA, Glover JL, Bang N, et al. Clotting competence Broadie TA, Glover JL, Bang N, et al. Clotting competence of intracavity blo

4 Jacobs LM, Hsieh JW. A clinical review of autotransfusion and its role in trauma. $\mathcal{F A M A} 1984 ; 251: 3283-7$.

5 Young GP, Purcell TB. Emergency autotransfusion. Ann Emerg Med 1983;12:180-6.

6 Klebanoff G. Intraoperative autotransfusion with the Bentley ATS-100. Surgery 1978;84:708-12. 